\title{
Evaluation of wood material models for the numerical assessment of cutting forces in chipping processes
}

\author{
Philip Pichler $^{1} \cdot$ Martin Leitner ${ }^{1} \cdot$ Florian Grün$^{1} \cdot$ Christoph Guster $^{2}$
}

\begin{abstract}
Generally, wood chipping represents an important procedure in the wood processing and forestry industry. To improve structural components like chipping tools, knowledge of the properties of local timber including resistance against chipping as well as the dynamically acting process forces is of utmost significance. The aim of this work is to experimentally evaluate service-induced stresses on machinery parts to create a numerical material model, which is capable of revealing similar resistance against cutting as natural wood. To this end, a small-scale cutting machine has been designed, incorporating a bladeholder with strain gauges applied, measuring the resulting mechanical stresses during the chipping process by focussing on different wood species. Spruce is utilized as a variety with a lower density and European beech for higher density timber applications. The test results demonstrate a distinct difference by cutting both materials, whereby European beech indicates more than twice the resistance against chipping compared to spruce. Setting two different, relatively acute rake angles on the cutting tool does not reveal a fundamental difference for chipping. To evaluate the numerical wood material model, an isotropic ductile damage model, usually applied to ductile metals, was implemented in this study. Based on a sensitivity study of the material properties in the course of the numerical simulation, a possible approach is presented that explains how to change the cutting resistance, depending on the blade movement direction and the angle of the main grain of the timber. In a comparison of different types of mechanical stress from the numerical analysis and experimental tests, the
\end{abstract}

Philip Pichler

philip.pichler@unileoben.ac.at

1 Chair of Mechanical Engineering, Montanuniversiät Leoben, Franz-Josef Straße 18, 8700 Leoben, Austria

2 Komptech GmbH, Kühau 37, 8130 Frohnleiten, Austria 
results exhibit strong correlation. Element damage and deletion correspond at similar load levels, exhibiting a deviation of no more than $24 \%$.

\section{Introduction}

When calculating structural stress in components subjected to heavy loads using modern, standard finite element analysis, it is of great importance to define load cases and scenarios. Misconceptions lead to incorrect results and furthermore, a possible non-conservative assessment may occur (Blaauwendraad 2010). Wood as a quite complex, anisotropic material, exhibits properties that vary enormously, depending on the direction of fibre orientation. Previous studies in the field of woodworking provide an insight into acting forces on low chip thickness. For cutting depths of about $1 \mathrm{~mm}$, the loads on the operating blades are on a comparably low level. Hereby, the main focus is on the fabrication of wooden products like furniture or semifinished materials for the construction industry. Many influences on the cutting force in woodworking have firstly been researched by Kivimaa (1950) and include blade geometry and sharpness, machining speed, wood density, moisture and temperature. Further investigation on an experimental basis to analytically calculate the acting forces is shown by Porankiewicz et al. (2011) and Axelsson et al. (1993). Moreover, analytical methods to calculate forces caused by sawing rather uncommonly processed tropical woods have been investigated by Cristóvão (2013). Machining in the forest industry means significantly more cutting service, in turn leading to higher mechanical loads on the structural parts. In this case, the closest attention is devoted to the cut chip itself. Large industrial heating boilers that generate more than $1 \mathrm{MW}$ require chips approximately $35 \mathrm{~mm}$ in size (Kofman 2006). Research on measurements of such cutting dimensions is quite rare and difficult to put into practice. Recently, Pfeiffer et al. (2015a, b) and Hatton et al. (2015) utilized huge pendulums with applied force sensors to measure loads acting during the chipping process or to simulate the chip building process with the discrete element method (DEM). Another method to measure forces on such scales is possible with machine built-in sensors shown in Hellström et al. (2011) and Hellström (2010). On the basis of the aforementioned investigations as well as preliminary studies presented in Pichler et al. (2016a, b), this paper deals with the determination of the cutting resistance of wood by numerical methods, whereby experimental tests on small-scale samples are conducted to help customize the parameters for the material models in explicit finite element analysis (Fig. 1). The aim of this work is to achieve a model, which allows an assessment of the cutting force distribution for greater cutting depths and additionally deals with an approach

Fig. 1 Methodology to evaluate wood material model

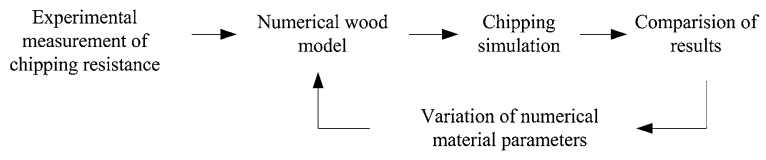


to numerically estimate the resulting mechanical stresses caused by the dynamic chipping process.

\section{Materials and methods}

To consider different representatives of wood species from lower and higher density, spruce (Picea, moisture content of 10.1\%) and European beech (Fagus sylvatica, moisture content of $6.5 \%$ ) are utilized within the experimental cutting tests. The laboratory chipping machine consists of a rotating arm with a diameter of $660 \mathrm{~mm}$, mounted on a torque motor with a nominal power of $1.51 \mathrm{~kW}$. On this arm, a wood specimen with dimensions of $60 \times 60 \times 300 \mathrm{~mm}^{3}$ is fixed. A defined cutting depth is manually adjusted by a cross-table (Fig. 2). After rotation of $330^{\circ}$, the rotating arm reaches $150 \mathrm{rpm}$ equalling an impact speed on the cutting blade of $5 \mathrm{~m} / \mathrm{s}$. This value is limited by the operating torque motor, which guarantees a constant impact velocity after acceleration in less than one full revolution of the rotating arm and the whole width of the cutting tool for a single cut is in operation. The second wooden part on the rotating arm besides the wood specimen (see Fig. 2) serves as dynamic mass balance. The ensured deceleration of the arm is also realized at $330^{\circ}$ rotation. Therefore, no additional impact of the wooden specimen after one cutting process occurs. The cutting blade is made of hardened cold working steel $75 \mathrm{Cr} 1,4 \mathrm{~mm}$ wide. Measurements on a digital microscope with $3 \mathrm{D}$ surface profiling prior to testing show that the corner radius exhibits values of 35 up to $40 \mu \mathrm{m}$ between the rake and the clearance surface of the applied tool. These conditions comply with Ekevad et al. (2012), whereby the blade shows an adequately sharp condition.

Each cut per wood species and growth ring alignment (transversal, longitudinal, diagonal) is performed between two and four times (see Fig. 3), leading to at least nine cuts per cutting depth perpendicular to grain direction (GD). At the beginning
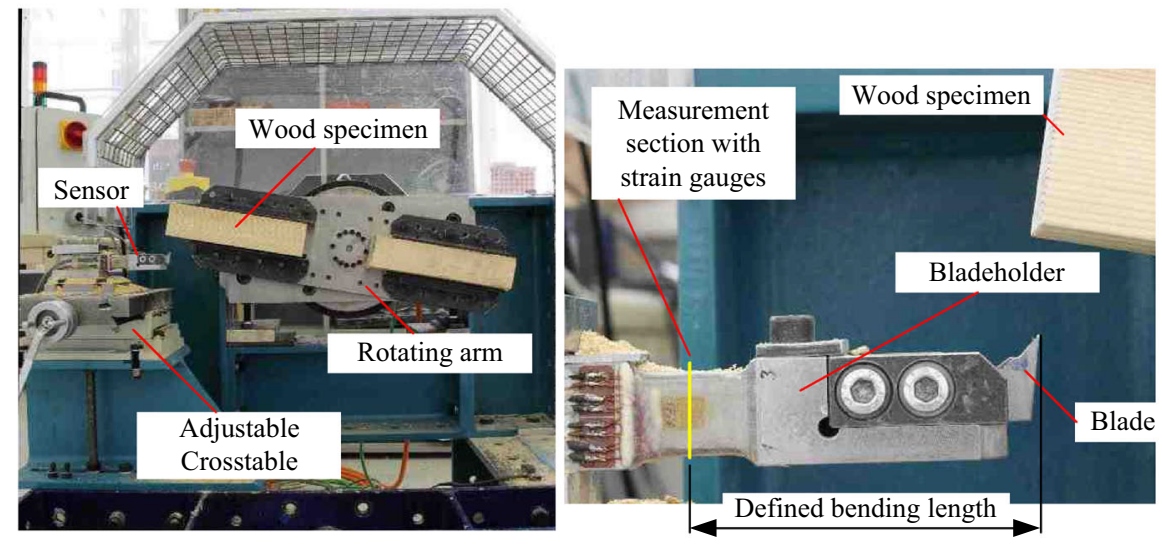

Fig. 2 Chipping test set-up and detailed view of the bladeholder with applied strain gauges and fixed blade 


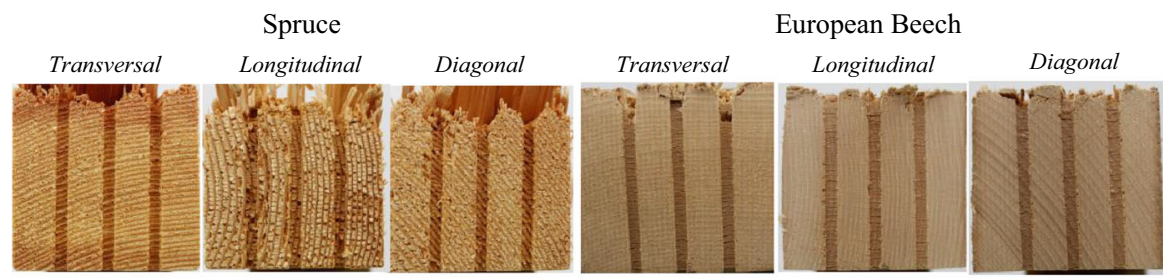

Fig. 3 Chipped wood species of spruce and European beech perpendicular to grain direction $(\perp)$ in different growth ring alignment

of testing, the wood sample is processed to achieve a cylindrical top surface. This fundamental step ensures consistent cutting depths for the tests. After the aforementioned two to four cuts per defined cutting depth this preparing-step is repeated to remove grooves. It is followed by tests with the next higher cutting depth on again cylindrical top surface. For comparison of the experimental and numerical results, the blade exhibits a rake angle of $35^{\circ}$ and a clearance angle of $8^{\circ}$. Additional tests show the difference by using a higher rake angle of $47^{\circ}$ with the same clearance angle. In this work, all cuts are conducted perpendicular to the main grain direction with a change in the growth ring alignment in transversal, diagonal and longitudinal directions, because it represents the main feeding direction of drum chippers. The cutting depth is limited for spruce to $4 \mathrm{~mm}$ and for European beech to $2.5 \mathrm{~mm}$. Figure 3 represents the three cutting grooves from the tests with the highest cutting depth setting in different growth ring alignments at the spruce and European beech specimen.

To measure the chipping resistance or rather the bending stress due to acting forces with compensation of the normal stress according to Hoffmann (2004) by cutting wood, strain gauges are applied in full bridge arrangement on a defined area of the blade bracket with a bending distance until the measurement area of $97.5 \mathrm{~mm}$ and a cross section of $20 \times 20 \mathrm{~mm}$. Additionally attached strain gauges on the side of the bladeholder ensure a proper control of the experiments; thus, straight cuts are guaranteed without the influence of horizontally acting lateral cutting forces. A data-logger with a sampling rate of $9600 \mathrm{~Hz}$ is utilized to accurately measure the highly dynamic cutting process.

To evaluate parameters for the numerical material model, the bladeholder and the tied cutting blade are implemented within an explicit three-dimensional simulation in the software suite $A B A Q U S$ and encased equally to the experimental test set-up to ensure comparable boundary conditions (Fig. 4). The blade is set-up as a rigid body, and the bladeholder is modelled with usually known material properties for steel $(E=210,000 \mathrm{MPa}, v=0.3)$. Both parts are meshed with linear, tetragonal C3D4 $(A B A Q U S)$ elements. The wooden specimen consists of hexagonal, linear C3D8 (ABAQUS) elements and element sizes of 0.5 or $0.2 \mathrm{~mm}$ (for $1 \mathrm{~mm}$ cutting depth) in cutting area.

The mesh in the measuring area, where strain gauges are applied in the experiments, is kept relatively fine to properly analyse the mechanical stresses. An area in the size of a utilized strain gauge is separated to a node set, and the mesh size 


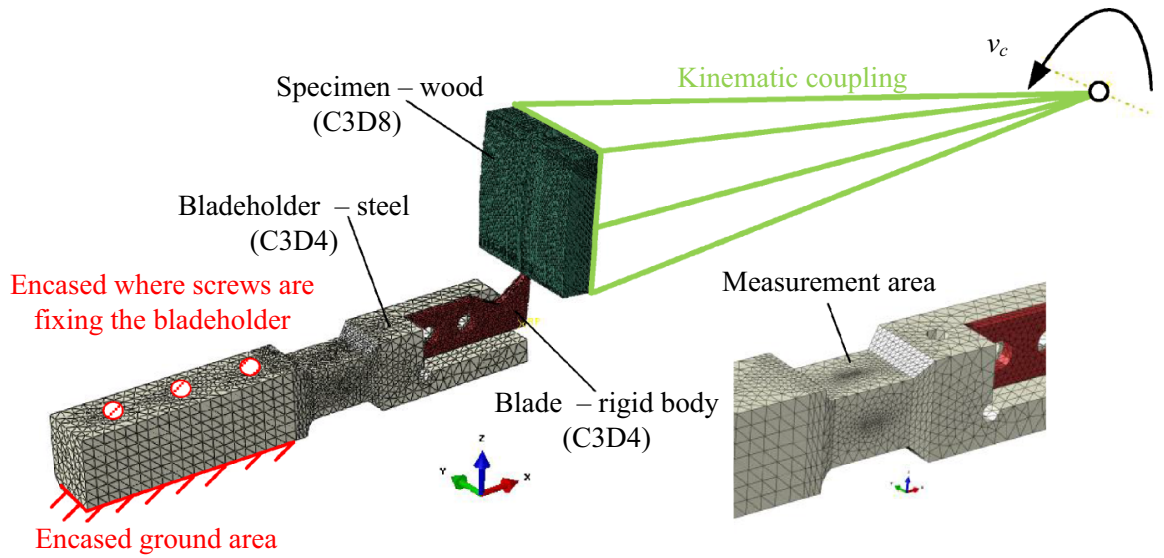

Fig. 4 Illustration of numerical model with included mesh, boundary conditions and a detailed view on the mesh at the mechanical stress measurement area

is limited to $1 \mathrm{~mm}$. For comparison with the experimental test, the mean stress of the included set in X-direction is used from the upper side and the underside of the bladeholder measurement area. The boundary conditions are similar to the experimental test. The numerical wood specimen is connected with a kinematic coupling to a reference point in the rotation centre, which ensures a constant cutting speed $v_{\mathrm{c}}$ of $5 \mathrm{~m} / \mathrm{s}$ during the simulation. The rigid blade is modelled with a tip corner radius equal to the previously shown measurements and is tied to the bladeholder. The bladeholder itself is encased on the ground surface and on round areas, where it is fixed into place by screws, as seen in the experimental set-up.

The contact between the wooden part and the blade surfaces is modelled as general contact with a friction coefficient of 0.2 . Finding the contact after element deletion on the interior element surfaces is defined by adapting the ABAQUS input file, in accordance with ABAQUS Inc. (2013a), via manually including the created interior surfaces to the contact definition. The resistance of wood against chipping is numerically represented based on findings by Niemz and Ozyhar (2011), Resch and Kaliske (2010), Schmidt and Kaliske (2006) and Jenkel and Kaliske (2014) applying an ideal elasto-plastic, ductile damage model with zero energy damage evolution, which is usually implemented for ductile metals (Table 1), according to Prantl et al. (2013). The concept of integrating the anisotropic material behaviour in the

Table 1 Applied material data for numerical damage model of wooden specimen

\begin{tabular}{|c|c|c|c|c|c|}
\hline Wood & $\begin{array}{l}\text { Cutting direction to grain } \\
\text { direction }\end{array}$ & $\begin{array}{l}\rho(\mathrm{kg} / \\
\left.\mathrm{m}^{3}\right)\end{array}$ & $E(\mathrm{MPa})$ & $\begin{array}{l}\sigma_{\mathrm{f}} \\
(\mathrm{MPa})\end{array}$ & $\begin{array}{l}\varepsilon_{\mathrm{f}} \\
\text { (normalized) }\end{array}$ \\
\hline \multirow[t]{2}{*}{ Spruce } & Perpendicular & 470 & 13,200 & 64 & 1 \\
\hline & Parallel & & 623 & 6.4 & 5.83 \\
\hline \multirow{2}{*}{$\begin{array}{c}\text { European } \\
\text { beech }\end{array}$} & Perpendicular & 720 & 15,400 & 105 & 1.25 \\
\hline & Parallel & & 2200 & 10.5 & 5.41 \\
\hline
\end{tabular}


simulation is to split the cut part into areas with changing isotropic material parameters, depending on the tool movement direction (cutting direction) and the main grain direction with respect to established Young's modulus $E$ and fracture stress $\sigma_{\mathrm{f}}$, ABAQUS Inc. (2013b). To generate the resistance of the numerical material in accordance with the experiment, a numerical parameter study on the fracture strain $\varepsilon_{\mathrm{f}}$ is performed. Figure 5 demonstrates the principle of the presented material model. A dependency of strain rate and the material triaxiality on the failure strain is not considered in this work. Based on the knowledge that chipping perpendicular to grain direction leads to a higher resistance than parallel to grain (Kivimaa 1950) the material parameter is changing in the simulation. On the one hand, for the numerical analysis of cutting direction perpendicular to grain direction the upper values acquainted for the elastic modulus $E_{\mathrm{C}, \perp}$ and the fracture stress $\sigma_{\mathrm{f}, \perp}$ are employed by a relatively low kept fracture strain $\varepsilon_{\mathrm{f}, \perp}$. In contrast, the approach for chipping parallel to grain operates on a converse approach with the lower values for $E_{\mathrm{C}, / /}$ and $\sigma_{\mathrm{f}, / /}$ and a higher assumed $\varepsilon_{\mathrm{f}, / /}$. The simulated results are compared with the experimental tests, where cuts were performed perpendicular to grain direction. The validation for chipping parallel to grain direction is carried out on the basis of the investigation by Kivimaa (1950). Thereby, the resistance of chipping wood in the main tangential and axial direction (parallel to grain) is in comparison to the radial direction (perpendicular to grain) less than two times weaker.

\section{Results and discussion}

Figure $6 \mathrm{a}-\mathrm{d}$ demonstrates the dependency of the measured maximum bending stress on the bladeholder during cutting of the wood species European beech and spruce. In general, it is recognizable that the chipping of lower density wood leads to a reduction in cutting resistance. The tests were stopped once the higher density wood

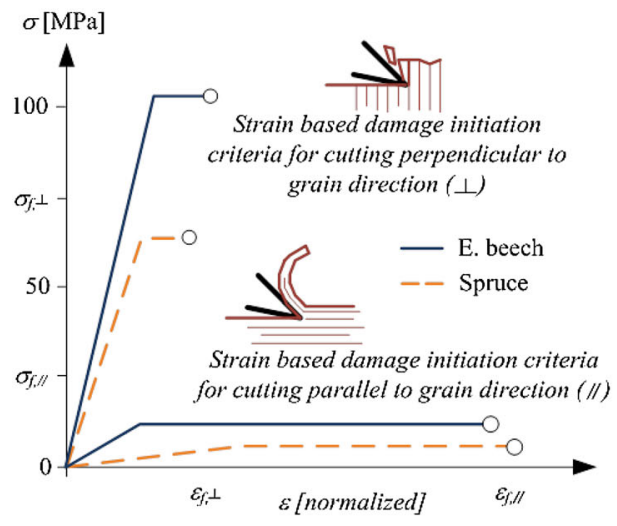

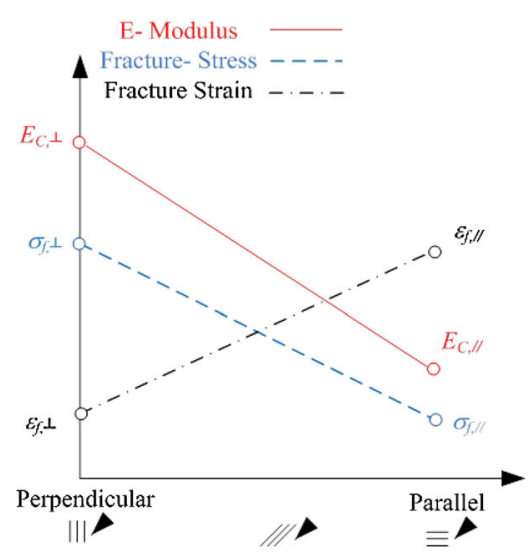

Cutting direction to grain direction

Fig. 5 Model for numerical material parameter change depending on the angle between the wood grain direction and the movement direction of the cutting tool 
had been cut at $2.5 \mathrm{~mm}$ depth, whereby spruce ended up after $4 \mathrm{~mm}$ because of the limitation of the test rig. By considering the chipping with different rake angles, it was observed that there is not as much contradiction as expected when cutting higher density wood (European beech). Tables 3 and 4 summarize the maximum bending stresses measured for the two different wood species including information about the growth ring alignment of each test, as presented within a preliminary study in Pichler et al. (2016b). The utilized mathematical fit according to Eq. 1 shows approximately the same level. Focusing on the chipping resistance of spruce with different rake angles, it is recognizable that the scattering of the measurements decreases with increasing rake angle and the prognosis for higher cutting depth shows slightly lower bending stresses. Equation 1 describes the mathematical fit of the measured bending stresses over the cutting depth $t$, whereby $a$ and $b$ are coefficients of the fit equation. Table 2 shows the parameters for $a$ and $b$. Considering the values for the exponent $b$, it can be concluded that a linear context is featured; however, a declining behaviour is recognizable. These characteristics have also been mentioned in investigations by Maier (1983), and values to calculate the mean cutting forces during woodworking for different wood species and cutting directions were performed by Wagenführ and Scholz (2012), whereby they propose a hyperbolic distribution with an exponent of $b=0.5$ (Eq. 2).

(a)

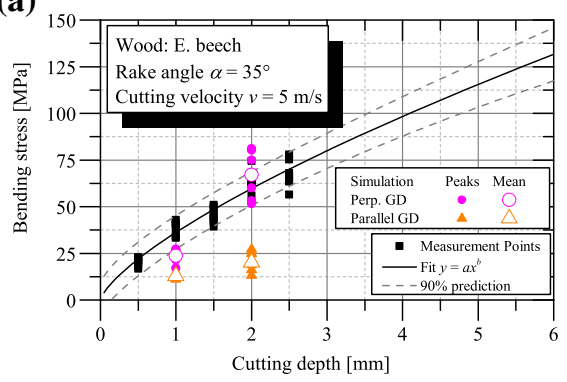

(c)

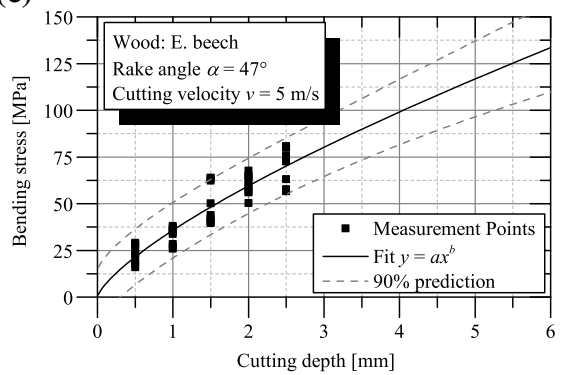

(b)

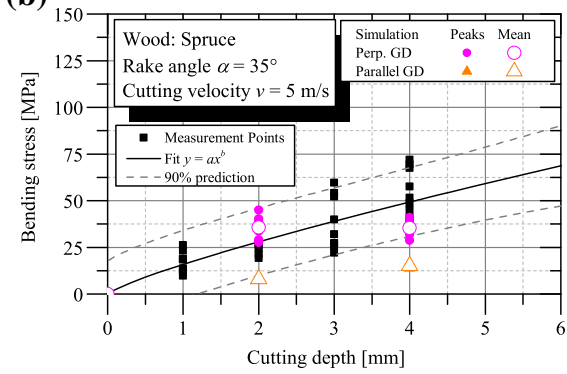

(d)

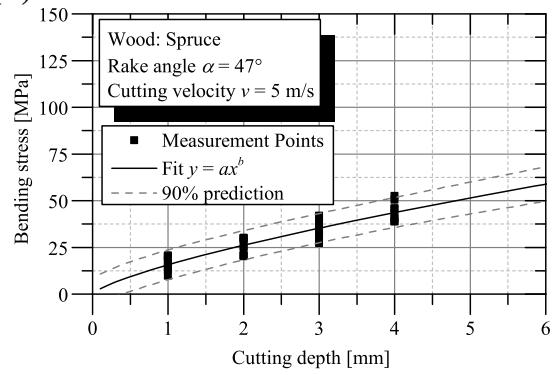

Fig. 6 Dependency of the measured bending stress on the bladeholder on the cutting depth for chipping E. beech (left) and spruce (right) with different rake angles and a comparison of the experimental data with the numerical results for cutting with a rake angle of $35^{\circ}(\mathbf{a}, \mathbf{b})$ 
Table 2 List of parameters for mathematical fit equation

\begin{tabular}{llllll}
\hline Wood/Parameter & Rake angle $\alpha\left(^{\circ}\right)$ & $a$ & Standard deviation of $a$ & $b$ & Standard deviation of $b$ \\
\hline Spruce & 35 & 15.86 & 2.58 & 0.82 & 0.14 \\
Spruce & 47 & 15.74 & 1.16 & 0.74 & 0.06 \\
European beech & 35 & 36.27 & 1.04 & 0.72 & 0.04 \\
European beech & 47 & 35.79 & 1.71 & 0.73 & 0.07 \\
\hline
\end{tabular}

$$
\begin{gathered}
\sigma_{b}=a \cdot t^{b} \\
F_{\mathrm{c}} \sim t^{0.5}
\end{gathered}
$$

The observed deviation in this work can be described by the fact that there is no flank profile meaning that the blade full friction on the lateral edges arises. Furthermore, the maximum of the bending stress during a cut is invoked instead of a mean value over the whole cutting time. In Fig. 6a, b, the results of the numerical analysis are also illustrated.

For a comparison of the experimental chipping tests with the simulation, the numerically calculated peaks of the bending stress and their mean value in the defined measurement area are included for the rake angle of $35^{\circ}$. The stresses in the simulation—just before element deletion - are at approximately the same level as measured in the experiment, with an average deviation of $24 \%$. By changing the numerical wood material parameters for cutting perpendicular and parallel to grain direction there is, on the one hand, a change in the calculated stresses in the measurement area noticeable, on the other hand, also a variation in the visual results. Figure 7 demonstrates the graphic results from the simulation for chipping with the material data of spruce and European beech at different cutting depths. Facilitating the material data for cutting perpendicular to the grain leads to a fairly rapid element deletion, and a few elements have been removed from the main specimen (Fig. 7a-d). This represents brittle material behaviour, where the applied elastic modulus $E_{\mathrm{C}, \perp}$, and the fracture stress $\sigma_{\mathrm{f}, \perp}$ are elevated and the implemented fracture strain $\varepsilon_{\mathrm{f}}$ is kept at a relatively low value. Detailed chip production as in a slabber process is not possible at this stage of the numerical simulation, because the elements are too rapidly deleted resulting in a decrease in element volume. Therefore, a finer mesh and hence, increased calculation resources would be required or alternatively, another simulation approach like DEM, leading to adequate visual chip production (see Pfeiffer et al. 2015b). To include wood anisotropy in the numerical simulation, approaches from Hashin (1980) and Puck (1998) could be considered in future investigations. By utilization of material data for chipping parallel to the grain with lower $E_{\mathrm{C}, / /}$ and $\sigma_{\mathrm{f}, / /}$, the numerical chipping process is represented by a flowing chip. Hence, the process does not lead to a separate detachment of elements from the main wooden part. Elements on the blade tip are removed, but other elements are still connected and build a roll off chip (Fig. 7e-h). These phenomena can be described, because of the higher assumed 

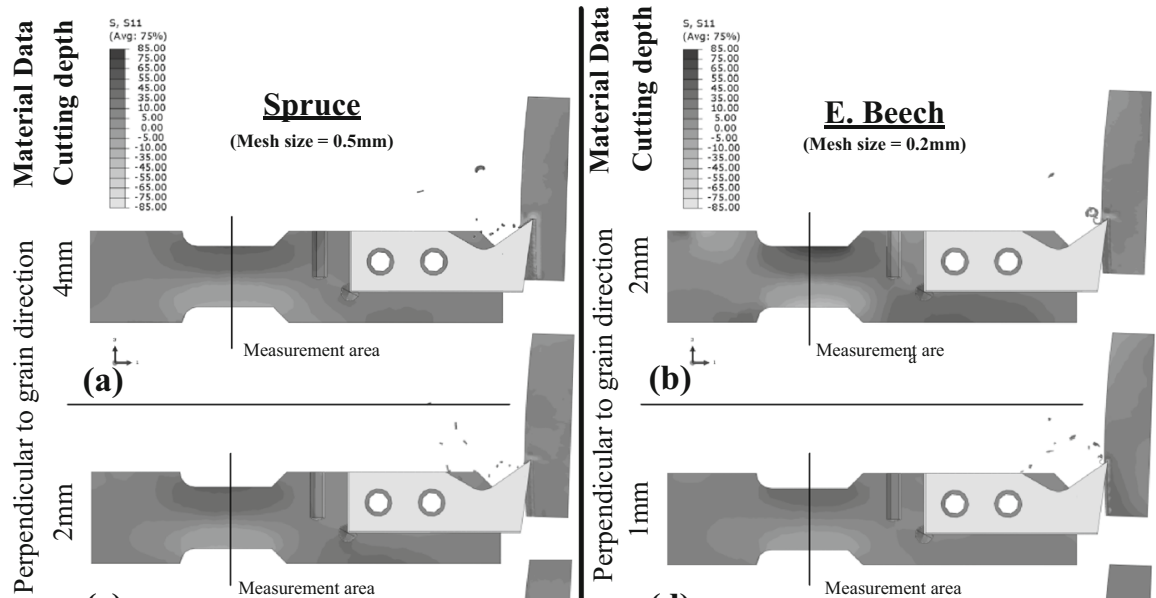

(c)

\section{Spruce}

$($ Mesh size $=0.5 \mathrm{~mm})$

Mesh size $=0.2 \mathrm{~mm}$
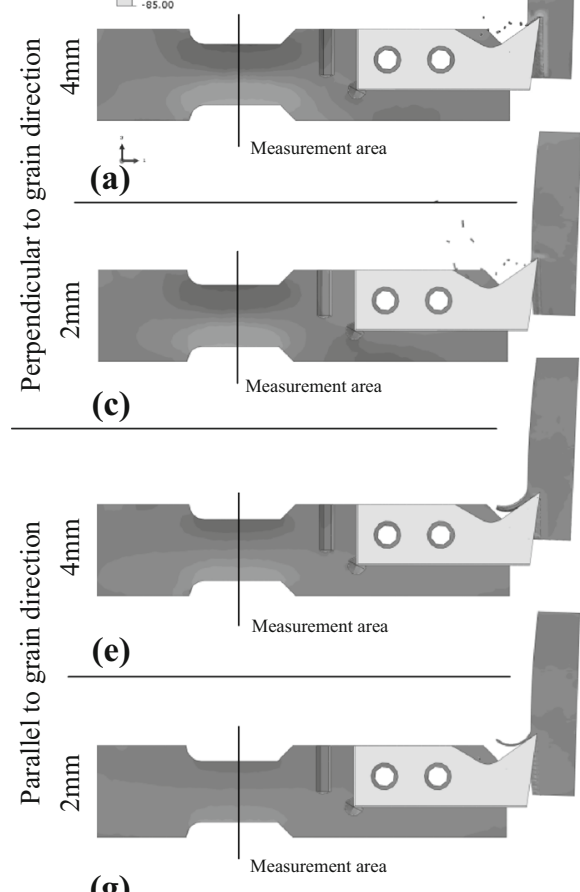

(d)

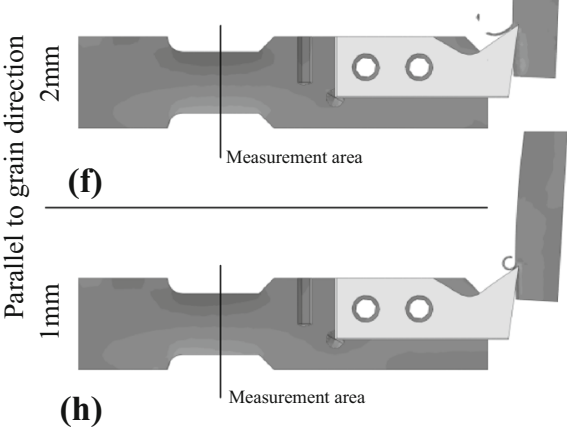

Fig. 7 Change in the graphical numerical results for different material parameters for cutting spruce or E. beech perpendicular or parallel to the grain

Fig. 8 Temporary course of stresses as a result of the numerical analysis

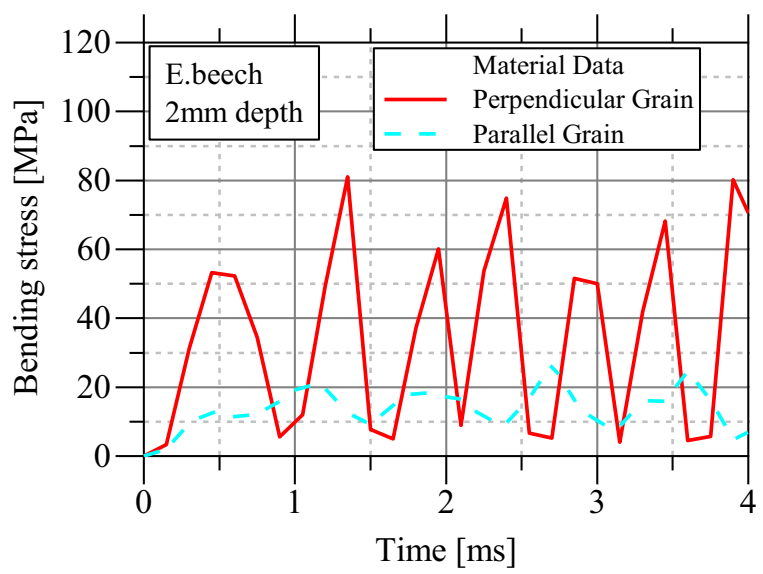


Table 3 List of experimentally determined maximum bending stresses caused by the resistance of spruce

\begin{tabular}{|c|c|c|c|c|c|}
\hline \multicolumn{6}{|l|}{ Spruce } \\
\hline \multicolumn{3}{|c|}{ Rake angle $35^{\circ}$} & \multicolumn{3}{|c|}{ Rake angle $47^{\circ}$} \\
\hline $\begin{array}{l}\text { Growth ring } \\
\text { alignment }^{\mathrm{a}}\end{array}$ & $\begin{array}{l}\text { Cutting } \\
\text { depth }(\mathrm{mm})\end{array}$ & $\begin{array}{l}\text { Max. bending } \\
\text { stress }(\mathrm{MPa})\end{array}$ & $\begin{array}{l}\text { Growth ring } \\
\text { alignment }\end{array}$ & $\begin{array}{l}\text { Cutting } \\
\text { depth (mm) }\end{array}$ & $\begin{array}{l}\text { Max. bending } \\
\text { stress }(\mathrm{MPa})\end{array}$ \\
\hline DIA & 1 & 26.26 & DIA & 1 & 19.76 \\
\hline DIA & 1 & 18.69 & DIA & 1 & 13.82 \\
\hline DIA & 1 & 23.30 & DIA & 1 & 17.17 \\
\hline LONG & 1 & 9.80 & LONG & 1 & 9.79 \\
\hline LONG & 1 & 18.97 & LONG & 1 & 12.77 \\
\hline LONG & 1 & 18.51 & LONG & 1 & 14.75 \\
\hline TRA & 1 & 13.10 & TRA & 1 & 20.72 \\
\hline TRA & 1 & 13.65 & TRA & 1 & 18.12 \\
\hline TRA & 1 & 11.62 & TRA & 1 & 20.37 \\
\hline DIA & 2 & 35.91 & DIA & 2 & 28.80 \\
\hline DIA & 2 & 36.20 & DIA & 2 & 30.10 \\
\hline DIA & 2 & 35.81 & DIA & 2 & 29.94 \\
\hline LONG & 2 & 19.28 & LONG & 2 & 20.69 \\
\hline LONG & 2 & 26.00 & LONG & 2 & 20.23 \\
\hline LONG & 2 & 24.02 & LONG & 2 & 24.29 \\
\hline TRA & 2 & 21.50 & TRA & 2 & 25.62 \\
\hline TRA & 2 & 27.13 & TRA & 2 & 20.52 \\
\hline TRA & 2 & 27.35 & TRA & 2 & 29.65 \\
\hline DIA & 3 & 52.20 & DIA & 3 & 37.10 \\
\hline DIA & 3 & 54.05 & DIA & 3 & 41.59 \\
\hline DIA & 3 & 59.65 & DIA & 3 & 33.07 \\
\hline LONG & 3 & 22.05 & LONG & 3 & 27.21 \\
\hline LONG & 3 & 39.91 & LONG & 3 & 32.64 \\
\hline LONG & 3 & 32.01 & LONG & 3 & 40.80 \\
\hline TRA & 3 & 27.21 & TRA & 3 & 30.89 \\
\hline TRA & 3 & 26.77 & TRA & 3 & 38.37 \\
\hline TRA & 3 & 26.01 & TRA & 3 & 42.03 \\
\hline DIA & 4 & 67.58 & DIA & 4 & 52.46 \\
\hline DIA & 4 & 71.99 & DIA & 4 & 45.97 \\
\hline DIA & 4 & 69.37 & DIA & 4 & 50.40 \\
\hline LONG & 4 & 39.52 & LONG & 4 & 38.89 \\
\hline LONG & 4 & 51.62 & LONG & 4 & 38.85 \\
\hline LONG & 4 & 41.21 & LONG & 4 & 45.67 \\
\hline TRA & 4 & 57.54 & TRA & 4 & 40.54 \\
\hline TRA & 4 & 48.70 & TRA & 4 & 42.68 \\
\hline TRA & 4 & 45.16 & & & \\
\hline
\end{tabular}

${ }^{\mathrm{a}}$ Growth ring alignment: TRA transversal, LONG longitudinal, DIA diagonal 
Table 4 List of experimentally determined maximum bending stresses caused by the resistance of E. beech

\begin{tabular}{|c|c|c|c|c|c|}
\hline \multicolumn{6}{|l|}{ Beech } \\
\hline \multicolumn{3}{|c|}{ Rake angle $35^{\circ}$} & \multicolumn{3}{|c|}{ Rake angle $47^{\circ}$} \\
\hline $\begin{array}{l}\text { Growth ring } \\
\text { alignment }^{\mathrm{a}}\end{array}$ & $\begin{array}{l}\text { Cutting } \\
\text { depth (mm) }\end{array}$ & $\begin{array}{l}\text { Max. bending } \\
\text { stress (MPa) }\end{array}$ & $\begin{array}{l}\text { Growth ring } \\
\text { alignment }\end{array}$ & $\begin{array}{l}\text { Cutting } \\
\text { depth (mm) }\end{array}$ & $\begin{array}{l}\text { Max. bending } \\
\text { stress (MPa) }\end{array}$ \\
\hline DIA & 0.5 & 19.96 & DIA & 0.5 & 29.01 \\
\hline DIA & 0.5 & 21.07 & DIA & 0.5 & 26.95 \\
\hline DIA & 0.5 & 22.58 & DIA & 0.5 & 23.32 \\
\hline LONG & 0.5 & 16.67 & LONG & 0.5 & 18.12 \\
\hline LONG & 0.5 & 18.01 & LONG & 0.5 & 19.57 \\
\hline LONG & 0.5 & 20.50 & LONG & 0.5 & 16.00 \\
\hline TRA & 0.5 & 21.06 & TRA & 0.5 & 28.27 \\
\hline TRA & 0.5 & 22.93 & TRA & 0.5 & 23.16 \\
\hline TRA & 0.5 & 22.56 & TRA & 0.5 & 23.54 \\
\hline DIA & 1 & 33.24 & DIA & 1 & 38.03 \\
\hline DIA & 1 & 38.17 & DIA & 1 & 35.89 \\
\hline DIA & 1 & 42.89 & DIA & 1 & 33.80 \\
\hline LONG & 1 & 34.72 & LONG & 1 & 25.82 \\
\hline LONG & 1 & 33.72 & LONG & 1 & 27.19 \\
\hline LONG & 1 & 41.52 & LONG & 1 & 28.33 \\
\hline TRA & 1 & 41.14 & TRA & 1 & 34.90 \\
\hline TRA & 1 & 41.40 & TRA & 1 & 37.27 \\
\hline TRA & 1 & 40.17 & TRA & 1 & 36.11 \\
\hline DIA & 1.5 & 42.96 & DIA & 1.5 & 40.55 \\
\hline DIA & 1.5 & 49.21 & DIA & 1.5 & 39.52 \\
\hline DIA & 1.5 & 50.90 & DIA & 1.5 & 40.09 \\
\hline LONG & 1.5 & 46.15 & DIA & 1.5 & 40.09 \\
\hline LONG & 1.5 & 45.53 & LONG & 1.5 & 43.87 \\
\hline LONG & 1.5 & 49.91 & LONG & 1.5 & 50.23 \\
\hline TRA & 1.5 & 39.29 & LONG & 1.5 & 42.33 \\
\hline TRA & 1.5 & 43.88 & TRA & 1.5 & 62.26 \\
\hline TRA & 1.5 & 42.15 & TRA & 1.5 & 63.82 \\
\hline DIA & 2 & 61.31 & TRA & 1.5 & 63.63 \\
\hline DIA & 2 & 66.77 & DIA & 2 & 64.58 \\
\hline DIA & 2 & 74.48 & DIA & 2 & 63.20 \\
\hline LONG & 2 & 61.78 & DIA & 2 & 59.08 \\
\hline LONG & 2 & 64.41 & LONG & 2 & 56.56 \\
\hline LONG & 2 & 62.27 & LONG & 2 & 56.06 \\
\hline TRA & 2 & 61.00 & LONG & 2 & 50.25 \\
\hline TRA & 2 & 62.80 & TRA & 2 & 60.11 \\
\hline TRA & 2 & 55.97 & TRA & 2 & 67.68 \\
\hline DIA & 2.5 & 64.10 & TRA & 2 & 65.11 \\
\hline
\end{tabular}


Table 4 continued

\begin{tabular}{|c|c|c|c|c|c|}
\hline \multicolumn{6}{|l|}{ Beech } \\
\hline \multicolumn{3}{|c|}{ Rake angle $35^{\circ}$} & \multicolumn{3}{|c|}{ Rake angle $47^{\circ}$} \\
\hline $\begin{array}{l}\text { Growth ring } \\
\text { alignment }^{\mathrm{a}}\end{array}$ & $\begin{array}{l}\text { Cutting } \\
\text { depth (mm) }\end{array}$ & $\begin{array}{l}\text { Max. bending } \\
\text { stress (MPa) }\end{array}$ & $\begin{array}{l}\text { Growth ring } \\
\text { alignment }\end{array}$ & $\begin{array}{l}\text { Cutting } \\
\text { depth (mm) }\end{array}$ & $\begin{array}{l}\text { Max. bending } \\
\text { stress (MPa) }\end{array}$ \\
\hline DIA & 2.5 & 67.95 & DIA & 2.5 & 72.56 \\
\hline DIA & 2.5 & 75.20 & DIA & 2.5 & 79.87 \\
\hline LONG & 2.5 & 63.39 & DIA & 2.5 & 75.62 \\
\hline LONG & 2.5 & 67.05 & LONG & 2.5 & 57.76 \\
\hline LONG & 2.5 & 65.74 & LONG & 2.5 & 56.61 \\
\hline TRA & 2.5 & 56.39 & LONG & 2.5 & 63.09 \\
\hline TRA & 2.5 & 77.21 & TRA & 2.5 & 100.15 \\
\hline \multirow[t]{2}{*}{ TRA } & 2.5 & 77.90 & TRA & 2.5 & 80.78 \\
\hline & & & TRA & 2.5 & 80.52 \\
\hline
\end{tabular}

${ }^{a}$ Growth ring alignment: TRA transversal, LONG longitudinal, DIA diagonal

fracture strain $\varepsilon_{\mathrm{f}}$, which imparts the material with added plasticity. The diagram in Fig. 8 illustrates the beginning of the temporal progress of the stresses on the bladeholder during the simulated cuts in Figs. 7b, $\mathrm{f}$ in the material data of European beech, cut perpendicular and parallel to the grain. The stresses show a noncontinuous distribution during the chipping process, because elements are repeatedly deleted and the cutting face on the blade has to find contact again with interior element areas of the rotating numerical wooden part. This depicted zigzag formation is pronounced by the utilization of the brittle material data for chipping perpendicular to grain direction, when elements are splintering off during the process. The cut with more plastic material (parallel to grain) parameters boasts a continuous contact on the chipping face on the blade.

\section{Conclusion}

This work illustrates a possibility to numerically calculate service-induced stresses on machinery parts occurring by means of the dynamic process of chipping wood. Therefore, a concept of a customized damage model is applied. It incorporates the wooden anisotropic behaviour for cuts with a variation of isotropic material parameters in dependence of the cutting and the wood grain direction. Herein, established material characteristics in different cutting directions are employed and a study on process-relevant variables has been performed to achieve a similar resistance against cutting to that provided in the test results. Experimental smallscale cutting tests were conducted to measure the cutting resistance of a relatively dry spruce specimen and European beech. The tests measured the marked dependence of the chipping depth on different rake angles. A nonlinear context and an independence of the rake angle from the cutting resistance of wood even at 
such high rake angles of $35^{\circ}$ and $47^{\circ}$ were observed. However, a higher rake angle leads to a decrease in the variation of the results especially when cutting lower density wood. Comparing the required chipping force, it is remarkable that the higher density wood of European beech leads to a 2.25 times higher resistance than the lower density spruce. These experimental results act as comparative values for the validation of the simulation. Following the adjustment of the unknown parameters in the numerical material model, a comparably minor deviation is recorded. Future investigations shall focus on the influence of wood exhibiting more moisture than in the presented numerical material model.

Acknowledgements Open access funding provided by Montanuniversität Leoben. This work was perpetrated at the Chair of Mechanical Engineering at the Montanuniversität Leoben, in cooperation with Komptech GmbH. Special thanks are given to the Austrian Research Promotion Agency (FFG), who founded the research project by funds of the Federal Ministry for Transport, Innovation and Technology (bmvit) and the Federal Ministry of Economics and Labour (BMWA), and to all the industry partners for the supply of material and the fabrication work done.

Open Access This article is distributed under the terms of the Creative Commons Attribution 4.0 International License (http://creativecommons.org/licenses/by/4.0/), which permits unrestricted use, distribution, and reproduction in any medium, provided you give appropriate credit to the original author(s) and the source, provide a link to the Creative Commons license, and indicate if changes were made.

\section{References}

ABAQUS Inc. (2013a) ABAQUS analysis user's guide (Version 6.13) 2.3.2 Element-based surface definition

ABAQUS Inc. (2013b) ABAQUS analysis user's guide (version 6.13) 24.2. Damage and failure for ductile metals

Axelsson BOM, Lundberg AS, Grönlund JA (1993) Studies of the main cutting force at and near a cutting edge. Holz Roh Werkst 51(1):43-48

Blaauwendraad J (2010) Plates and FEM. Surprises and pitfalls. Springer, Dordrecht

Cristóvão L (2013) Machining properties of wood-tool wear, cutting forces and tensioning of blades. $\mathrm{Ph} . \mathrm{D}$. thesis. Lulea University of Technology, Skelleftea, Sweden

Ekevad M, Cristóvão L, Marklund B (2012) Wear of teeth of circular saw blades. Wood Mater Sci Eng 7(3):150-153

Hashin Z (1980) Failure criteria for unidirectional fiber composites. J Appl Mech 47(2):329-334

Hatton B, Pot G, Bouzgarou BC, Gagnol V, Gogu G (2015) Experimental determination of delimbing forces and deformations in hardwood harvesting. Croat J Eng 36(1):43-53

Hellström L (2010) On the wood chipping process - a study on basic mechanism in order to optimize chip properties for pulping. Ph.D. thesis. Mid Sweden University, Sweden

Hellström LM, Gradin PA, Gulliksson M, Carlberg T (2011) A laboratory wood chipper for chipping under realistic conditions. Exp Mech 51(8):1309-1316

Hoffmann K (2004) An introduction to stress analysis and transducer design using strain gauges. www. hbm.com. Accessed 9 Apr 2017

Jenkel C, Kaliske M (2014) Finite element analysis of timber containing branches-an approach to model the grain course and the influence on the structural behaviour. Eng Struct 75:237-247

Kivimaa E (1950) Cutting force in woodworking. Ph.D. thesis. Finland's Institute of Technology, Helsinki 
Kofman PD (2006) Quality wood chip fuel. COFORD. Dublin (IRL) (Harvesting, transport and forest machinery, 6). http://www.coford.ie/media/coford/content/publications/projectreports/cofordconnects/ finalfuelquality.pdf. Accessed Nov 2016

Maier G (1983) Spanungstechnische Grundlagen der Hackschnitzelerzeugung in Trommelhackern (Technical basics of wood chips production in drum chippers). Holz Roh Werkst 41(10):437-439 (In German)

Niemz P, Ozyhar T (2011) Ermittlung elastomechanischer Kennwerte von Rotbuchenholz. (Determination of elasto-mechanical characteristics of European beech wood) Reference number: 2010.09. Final Report. ETH Zürich (In German)

Pfeiffer R, Collet R, Denaud LE, Fromentin G (2015a) Analysis of chip formation mechanisms and modelling of slabber process. Wood Sci Technol 49(1):41-58

Pfeiffer R, Lorong P, Ranc N (2015b) Simulation of green wood milling with discrete element method. In: 22nd international wood machining seminar, Bd. 22. International wood machining seminar. Quebec, Juni, pp 57-72

Pichler P, Leitner M, Grün F, Guster C (2016a) Experimental evaluation of cutting forces for chipping process and development of wood material model. In: Proceedings of WCTE 2016. World conference on timber engineering. Wien, 22-25 Aug. IMWS \& ITI, Vienna university of technology: TU Verlag, pp 2283-2290

Pichler P, Leitner M, Grün F (2016b) Validation of experimental tests and simulations of cutting forces during woodworking. In: WCCM XII \& APCOM VI. WCCM XII \& APCOM VI. Seoul, 24-29 Jul, pp $1220-1224$

Porankiewicz B, Axelsson B, Grönlund A, Marklund B (2011) Main and normal cutting forces by machining wood of Pinus sylvestris. BioResources 6(4):3687-3713

Prantl A, Ruzicka J, Spaniel M, Moravec M, Dzugan J, Konopik P (2013) Identification of ductile damage parameters. In: 3DS: 2013 SIMULIA community conference. 2013 SIMULIA community conference

Puck A (1998) Failure analysis of FRP laminates by means of physically based phenomenological models. Compos Sci Technol 58(7):1045-1067

Resch E, Kaliske M (2010) Three-dimensional numerical analyses of load-bearing behavior and failure of multiple double-shear dowel-type connections in timber engineering. Comput Struct 88(3-4):165-177

Schmidt J, Kaliske M (2006) Zur dreidimensionalen Materialmodellierung von Fichtenholz mittels eines Mehrflächen-Plastizitätsmodells (Three-dimensional material modelling of spruce wood using a multi-surface-plasticity model). Holz Roh Werkst 64(5):393-402 (In German)

Wagenführ A, Scholz F (2012) Taschenbuch der Holztechnik. (Paperback of wood technology), 2nd edn. Carl Hanser Verlag, Leipzig 